\title{
FNL/CAT/CP.- 79678
}

Cong. $93108-4$

OCT 19 19303

DENSIFICATION OF SALT-OCCLUDED ZEOLITE A POWDERS

TO A LEACH-RESISTANT MONOLITH* - -

Michele A. Lewis, Donald F. Fischer, and Christopiter D. Murphy**

Chemical Technology Division

"Energy Technology Division

Argonne National Laboratory

9700 South Cass Avenue

Argonne, Illinois 60439

To be presented at

Materials Research Society

Boston, Massachusetts

November 29-December 3, 1993

The wbmitted menuxpipt his been euthored

by contrector of the U.S. Govimment

undir contrit H.31-100ENG-38.

Accordinaly, the U.S Government retuine

nonexclusing

nonexclusin, royalty-fres licans torm of this

contribution, or dlow athers to do 20 , for

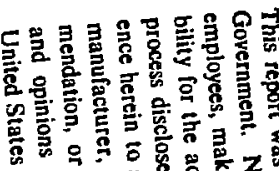

$0 \bigcirc 1$

U. S. Gevernment purpont.

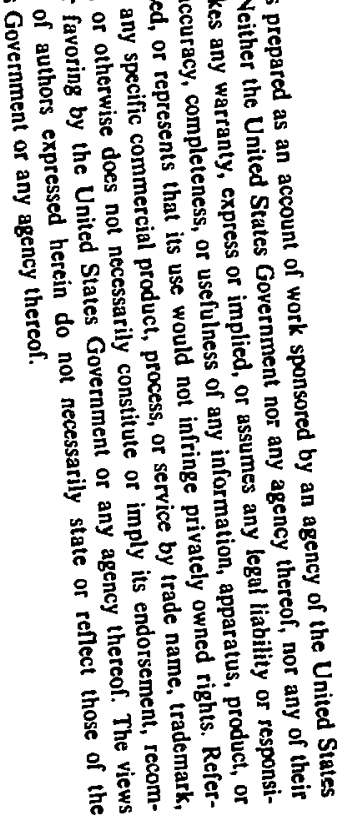

"Work supported by the U.S. Department of Energy, Nuclear Energy Research \& Development Program, under Contract W-31-109-Eng-38. 


\section{DENSIFICATION OF SALT-OCCLUDED ZEOLITE A POWDERS TO A LEACH-RESISTANT MONOLITH}

MICHELE A. LEWIS, DONALD F. FISCHER, AND CHAISTOPHER D. MURPHY*

Argonne National Laboratory, Chemical Technology Division, Argonne, lllinois 60439

*Argonne National Laboratory, Energy Technology Division, Argonne, llinois 60439

\section{ABSTRACT}

Pyrochenical processing of spent fuel from the Integral Fast Reactor (IFR) yields a salt waste of $\mathrm{LiCl}-\mathrm{KCl}$ that contains approximately $6 \mathrm{wt} \%$ fission products, primarily as $\mathrm{CsCl}$ and $\mathrm{SrCl}_{2}$. Past work has shown that zeolite $A$ will preferentially sorb cesium and strontium and will encapsulate the salt waste in a leach-resistant, radiation-resistant aluminosilicate matrix. However, a method is still needed to convert the salt-occluded zeolite powders into a form suitable for geologic disposal. We are thus investigating a method that forms bonded zeolite by hot pressing a mixture of glass frit and salt-occluded zeolite powders at $990 \mathrm{~K}\left(717^{\circ} \mathrm{C}\right)$ and $28 \mathrm{MPa}$. The leach resistance of the bonded zeolite was measured in static leach tesis run for 28 days in $363 \mathrm{~K}$ $\left(90^{\circ} \mathrm{C}\right)$ deionized water. Normalized release rates of all elements in the bonded zeolite were low, $<1 \mathrm{~g} / \mathrm{m}^{2} \mathrm{~d}$. Thus, the bonded zeolite may be a suitable waste form for IFF salt waste.

\section{INTRODUCTION}

The Integral Fast Reactor (IFR) is an advanced nuclear reactor under development at Argonne National Laboratory (ANL). This reactor design employs a metallic (U-Pu-Zr) fuel and an integral fuel cycle in which discharged core and blanket materials undergo pyrochemical processing and are refabricated in an on-site facility or a centralized fuel cycle facility. Pyrochemical processing of spent IFR fuel will result in a salt waste that contains approximately 6 wt\% fission products, primarily $\mathrm{CsCl}$ and $\mathrm{SrCl}_{2}$. The salt meets the definition of high level waste in $10 \mathrm{CFR} 60.2$, and the transuranic content of the salt is very low ( $<100 \mathrm{nCi} / \mathrm{g}$ ). Argonne has initiated a waste handling program to develop a mineral waste form that meets acceptance criteria for geologic oisposal. For this preliminary assessment, we have adopted the acceptance criteria and testing methods developed for the vitrified high level waste form from the Savannah River Site Defense Waste Processing Facility (DWPF) and West Valley Demonstration Project (WVDP) [1]. The waste will be processed as the chloride, thereby eliminating the need for conversion to other chemical forms. Because chloride salts are generally water soluble and affected by radiation, development of a suitable waste form is required. A promising method under development at ANL involves treating the salt with a zeolite and then densifying the treated zeolite with glass frit to form a leach-resistant monolithic mineral waste form.

In earlier work at ANL, salt-occluded zeolite $A$ was formed by passing simulated IFR waste salt through a column of zeolite $A$ at $723 \mathrm{~K}$ [2]. Most of the salt remained in the zeolite bed. After cooldown, the column was divided along the length of the column into quarters. Each 
quarter was washed to remove the e:iess salt. The washing procedure did not affect the zeolite's composition [3]. Analyses showed that ion exchange and salt occlusion had occurred. Nearly all of the sodium initially present in the zeolite was exchanged. The replacement of sodium by salt components occurred in the order: $\mathrm{Sr}>\mathrm{Ba}>\mathrm{Cs}>\mathrm{Li}>\mathrm{K}$. Approximately 11 salt "molecules" were occluded (sorbed within the zeolite's cavity), and each gram of zeolite was converted to $1.4 \mathrm{~g}$ of salt-occluded zeolite. Fission product (cesium, strontium, and barium) loading varied from $\sim 17 \mathrm{wt} \%$ at the top of the column to $\sim 1 \mathrm{wt} \%$ at the bottom. The remainder of the weight gain was due to the sorption of process wastes (lithium, potassium, and chloride ions). The washed salt-occluded zeolite powders were leach tested following a modified Product Consistency Test (PCT) procedure [4]. The results indicated that the leachabilities of the elements in salt-occluded zeolite powders are equal to or lower than the leachabilities of corresponding alements in Savannah River Laboratory borosilicate glass (designated SRL-202) $[2,5]$. In addition, preliminary irradiation tests showed that the salt-occluded zeolite is radiation stable to at least $10^{9} \mathrm{Rad}[2]$. That is, the x-ray diffraction spectrum of irradiated salt-occluded zeolite showed only minor changes when compared with the spectrum of an unirradiated sample. Samples of irradiated and unirradiated salt-occluded zeolite were leach tested in parallel experiments. The leachate $\mathrm{pH}$ and composition were not affected by the radiation. It was concluded that the salt-occluded zeolite is a promising waste form for the IFR salt if two problems can be solved. First, the excess salt has to be removed, preferably by a nonaqueous process. Second, the salt-occluded zeolite powders have to be converted into a solid monolith.

To handle the non-occluded salt remaining after waste loading. we are investigating the use of pressurized argon filtration followed by zeolite blending. That is, most of the salt is mechanically removed by filtration, then the remaining salt is converted to the occluded form by blending the residual material with new zeolite. Finally, the blended zeolite is mixed with glass frit and hot pressed to form a monolith. Experiments were undertaken to test each of these steps.

Experimental

General. All experiments were conducted in an argon glovebox. The atmosphere purity was maintained by passing argon through a Vacuum Atmospheres Dri-Train. ${ }^{\mathrm{TM}}$ The oxygen level was $<1 \mathrm{ppm}$. Simulated IFR salt was prepared by heating $\mathrm{KCl}-44.2 \mathrm{wt} \% \mathrm{LiCl}$ eutectic salt with $\mathrm{CsCl}$, $\mathrm{BaCl}_{2}, \mathrm{SrCl}_{2}, \mathrm{YCl}_{3}, \mathrm{Nal}$, and $\mathrm{NaCl}$ (to simulate the fuel element bond sodium) at $773 \mathrm{~K}$ for at least 48 hours. The eutectic salt was supplied by Lithcoa (Bessemer City, NC) and was used as received. All of the minor components were reagent grade chemicals and were dehydrated by heating to constant weight at $383 \mathrm{~K}$ prior to use. The zeolite A was supplied by the Molecular Sieves Division of UOP (Moorestown, NJ). The zeolite was dehydrated before use by heating it to $798 \mathrm{~K}$ with a dry nitrogen purge. Powdered glass frit was supplied by Miles Inc. (Baltimore, MD). Salt-occluded zeolite A with a homogeneous loading of fission products was prepared using a batch method. In a typical experiment, salt-occluded zeolite was prepared by heating $50 \mathrm{~g}$ of salt and $10 \mathrm{~g}$ of zeolite $A$ in separate quartz tubes to $723 \mathrm{~K}$, pouring the salt into the tube containing the zeolite, heating the mixture 72 hours, and then cooling quickly. 
Pressurized Argon Filtration. One method for removing the excess salt is to use pressurized gas to displace the salt and force it through the zeolite bed [6]. A sample containing saltoccluded zeolite and excess salt was transíerred to a stainless steel tube with a stainless steel frit welded onto its bottom. The frit was $0.16-\mathrm{cm}$ thick and had a nominal pore size of $5 \mu \mathrm{m}$. The top of the tube was connected to a gas delivery system. The bottom of the tube was positioned above a salt collection cup. The tube containing the sample was heated to $723 \mathrm{~K}$ in the furnace well of the glovebox. A thermocouple attached to the exterior of the sample tube moritored the sample temperature. The argon gas transfer line was pressurized in increments of 5 psig (34 $\mathrm{kPa}$ ) and held for $30 \mathrm{~min}$ at each increment up to $25 \mathrm{psig}(172 \mathrm{kPa}$ ) and for $15 \mathrm{~min}$ at $30 \mathrm{psig}$ (207 kPa). A temperature drop was typically observed at 25 and $30 \mathrm{psig}$ (172 and $207 \mathrm{kPa}$ ). The temperature drop indicated that the argon gas was freely flowing through the frit. After the temperature drop, further salt removal was minimal. In one run, nearly $75 \mathrm{wt} \%$ of the excess salt was removed and collected in the cup. The residual material in the stainless steel tube consisted of $14 \mathrm{~g}$ of salt-occluded zeolite and $\sim 9 \mathrm{~g}$ of excess salt. In another run, the amount of excess salt in the residual material was higher, about $\mathbf{5 0}$ wt\%. Thus, filtration is only partially successful in removing the excess salt.

Zeolite Blending. The method investigated ior treating the excess salt in the residual material was to occlude it in unreacted zeolite, thereby rendering it less water soluble. The residual material was transferred to a mortar and pulverized. The mixture was ground with the zeolite and heated overnight. The grinding and heating steps were repeated four or more times until all of the salt was occluded. The reaction progress was monitored with $x$-ray diffraction (XRD). The XRD intensity of the $\mathrm{NaCl}$ peak at a d-spacing of $2.82 \AA$ decreased as the amount of nonoccluded salt decreased. The zeolite blending process was considered complete when the intensity of the $2.82 \AA$ peak became very small.

Hot Pressing. The blended zeolite was then mixed with the glass powder. The amount of blended zeolite varied from 50 to $67 \mathrm{wt} \%$, with glass frit making up the balance. Two batches of blended zeolite with slightly different compositions were used. Approximately $4 \mathrm{~g}$ of each mixture was loaded into a graphite die, cold pressed to $41 \mathrm{MPa}$, and hot pressed in a uniaxial hot press at $990 \pm 3 \mathrm{~K}$ and $28 \mathrm{MPa}$. Further details of the hot pressing experiments will be published later. Six pellets were hot pressed.

The resulting pellets were cut into quarters with a Buehler diamond cut-off wheel. The quarters were then polished with abrasive papers up to 600 grit. No lubricant was used in either the cutting or polishing operations. The individual quarters were used for leach tests, as well as chemical and scanning electron microscopy (SEM) analyses.

Leach Tests. The MCC-1 test procedure was followed for the bonded zeolite pellet quarters [7]. The leach tests were run for 28 days in an oven at $363 \mathrm{~K}$. The leachant was deionized water. The normalized release rate (NRR) was measured using the formula,

$$
N R R(i)=C_{j} V / f_{j} A d
$$

where $C_{i}$ is the concentration of the element $i$ in the leachate in $g / m L, V$ is the volume of leachant in $\mathrm{mL}, \mathrm{f}_{\mathrm{i}}$ is the fraction of the element $i$ in the solid initially, $A$ is the macroscopic area of the solid in $\mathrm{m}^{2}$, and $\mathrm{d}$ is the duration of the test in days. The surface area was calculated from the 
dimensions of the quarter cylinder. The ratio of the surface area of the test specimen to the volume of deionized water was $0.1 \mathrm{~cm}^{-1}$.

Analyses. The compositions of the blended zeolite, glass frit, and bonded zeolite monoliths were analytically determined. Small samples of each, about $50 \mathrm{mg}$, were dissolved in a mixture of acids and heated overnight in a Parr bomb at $413 \mathrm{~K}$. The resulting solutions, as well as the leachates from the above tests, were analyzed by inductively coupled plasma-atomic emission spectroscopy (ICP-AES), atomic emission spectroscopy (AES), and ion chromatography (IC). The microstructure of the bonded zeolite pellet was studied with a scanning electron microscope, Model No. JEOL 5400. The porosity was measured with a Micromeritics Pore Sizer 9310 mercury porosimeter.

\section{Results and Discussion}

Composition. The compositions of two blended zeolite samples are given in Table 1 in units of weight percent and equivalents per unit cell. The calculation for determining equivalents per unit cell is explained in detail elsewhere $[2,3]$. The number of cation equivalents per unit cell (alkali metals, alkaline earth metals, and yttrium) varied from 20.2 to 20.6. Zeolite A requires 12 cation equivalents to balance the excess negative charge on the aluminosilicate matrix. The difference of 8.2-8.6 represents occluded cation equivalents. The number of occluded chloride and iodide iors varied from 8.3 to 8.5 (equivalent to $\sim 13 \mathrm{wt} \%$ ). Thus, the number of occluded cations and anions is in good agreement. These, along with the exchanged ions, represent the IFR salt waste loading in the blended zeolite.

The number of occluded cation-anion pairs in the blended zeolite $(\sim 8)$ was less than the number in washed (non-blended) salt-occluded zeolite ( 11). The composition of a washed sample is shown in Table 1 for comparison [2]. It may be that a large excess of salt is required to completely fill the zeolite's cavities. The fission product (cesium, strontium, barium, and yttrium) waste loading is also lower in the blended zeolite. The blended zeolite contained $\sim 3.0$ wt\% simulated fission products, while the washed salt-occluded zeolite contained up to $17 \mathrm{wt} \%$. The lower fission product waste loadings are the result of the comparatively large amounts of excess salt remaining after the pressurized argon filtration and the relatively low concentrations of fission products in this salt. Several methods are being investigated to increase the fission product loading in the blended zeolite.

The composition of the glass frit used to bond the blended zeolite powder is also given in Table I. This silicate glass contains relatively large amounts of calcium, strontium, and aluminum oxides. It has a softening point of $940 \mathrm{~K}$.

The compositions of most pellets were ralculated on the basis of the analyses for the blended zeolite and the glass frit and the amount of each. However, it was important to determine that hot pressing did not affect the composition of either the zeolite or the glass. For this reason, several pellets were crushed, and random samples of the particulates were analyzed. Results for two typical pellets are shown in Table I. Pellet 1 contained 67 wt\% blended zeolite (batch 1) and 33 wt $\%$ glass. Pellet 6 contained equal amounts of blended zeolite (batch 2) and glass. Comparison of the calculated and measured concentrations indicated that hot pressing did not 
Table 1. Composition of Solids

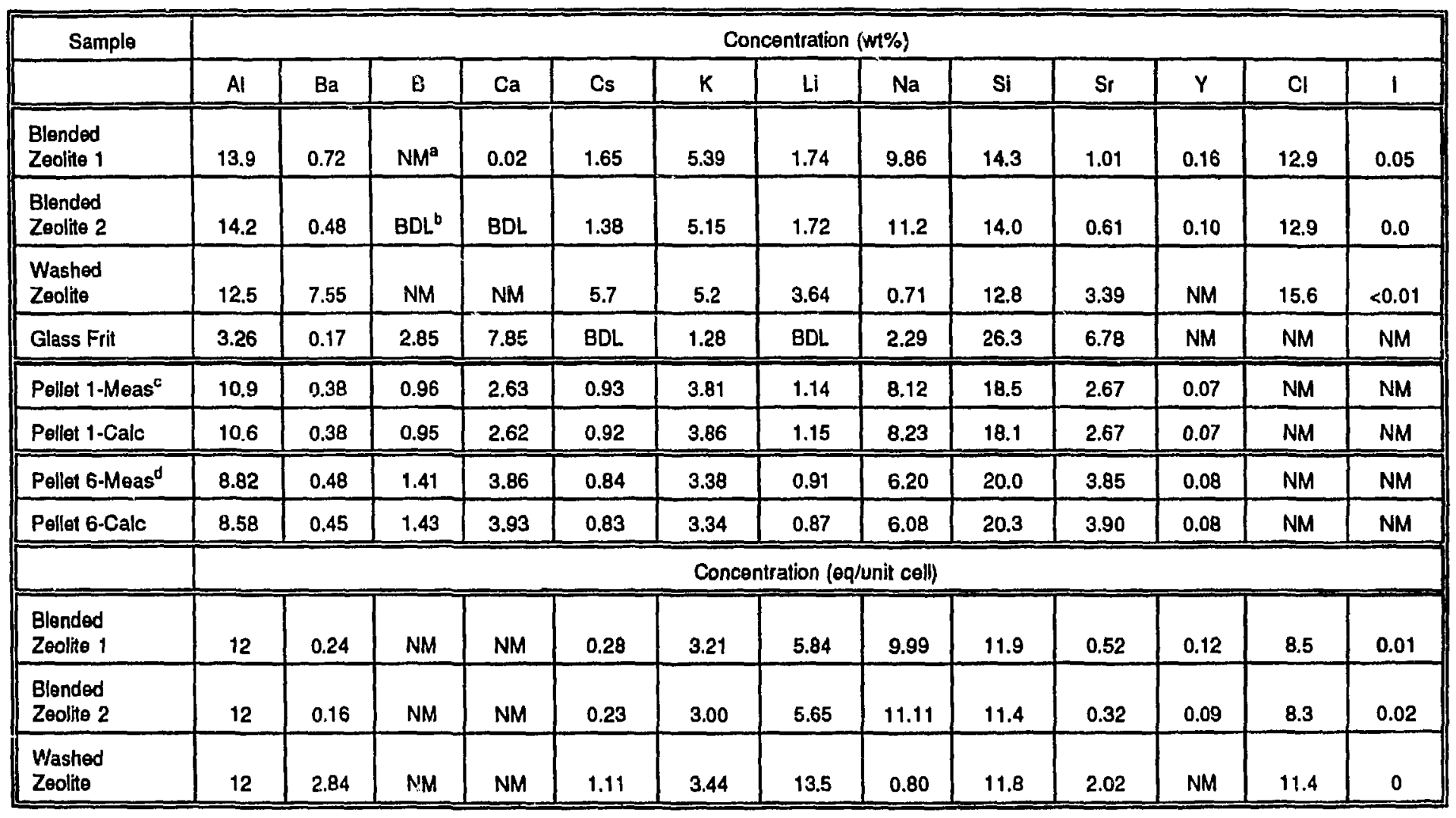

NM $=$ Not measured.

BDL = Below detection limit

Pellet 1 contained 67 wt\% blended zeolite (batch 2) and 33 wt\% glass frit.

d Peilef 6 contained equal amounts of blended zeolife (batch 1) and glass frit. The different amounts of glass in the pellets are most easily seen by comparing the concentrations of calcium and boron in the pellets. 
appreciably alter the composition of the blended zeolite, i.e., no significant volatilization of cesium or any other element occurred.

Leach Tests. The riormalized release rates (NRR) for the elements in the six bonded zeolite pellets are given in Table 2. Also shown are the average value and the standard deviation. The NRR was $<1 \mathrm{~g} / \mathrm{m}^{2} \mathrm{~d}$ for all of the elements in these pellets. The cesium NRR was $0.51 \pm 0.09$ $\mathrm{g} / \mathrm{m}^{2} \mathrm{~d}$, which is comparable to the cesium NRR from Savannah River borosilicate glass designated as SRP waste glass, $0.58 \mathrm{~g} / \mathrm{m}^{2} \mathrm{~d}[8]$. The silicon NRR from the bonded zeolite was $0.24 \pm 0.03 \mathrm{~g} / \mathrm{m}^{2} \mathrm{~d}$, which is lower than the value of $0.96 \mathrm{~g} / \mathrm{m}^{2} \mathrm{~d}$ determined for the SFP waste glass. The concentrations of yttrium in the leachates were less than the detection limits of $0.005 \mu \mathrm{g} / \mathrm{mL}$.

The strontium NRR was $0.17 \pm 0.05 \mathrm{~g} / \mathrm{m}^{2} \mathrm{~d}$ from the bonded zeolite and too low to be measured fron the SRP waste glass. However, there are two sources of strontium in the bonded zeolite pellets: the glass and the blended zeolite. The release of strontium from the glass is not as important as the release from the zeolite since the zeolite will eventually contain radioactive strontium. Therefore, experiments were completed to separate the two rates of release. In these experiments, the procedures used were the same as those given in the Experimental section, except that $\mathrm{LiCl}-\mathrm{KCl}$ eutectic (no fission products added) salt was substituted for the simulated IFR salt when the salt-occluded zeolite was prepared. Three pellets were produced and leach tested. The strontium NRR for the three pellets varied from 0.15 to $0.20 \mathrm{~g} / \mathrm{m}^{2} \mathrm{~d}$. The strontium NRR for the six pellets made with IFR salt varied from 0.10 to $0.24 \mathrm{~g} / \mathrm{m}^{2} \mathrm{~d}$. The conclusion was that most of the strontium was released from the glass and not from the blended zeolite. The variation in the strontium release rate will continue to be studied.

In general, the leach test results in Tabie 2 are comparable to those reported for SRP waste glass [8] and indicate that the bonded zeolite is a promising waste form fer IFR salt.

The results in Table $\|$ also show the effect of increasing waste loading by increasing the amount of blended zeolite in the glass-zeolite mixture. We concluded that leach resistance was not significantly affected when the amount of blended zeolite was increased from 50 to $67 \mathrm{wt} \%$. For the tested waste loadings, the variation in the NRR for all of the elements was within two standard deviations.

Microstructure. Scanning electron microscopy was used to examine the six pellets. Micrographs of the various pellets showed that the blended zeolite was distributed well throughout the glass matrix. At $500 \times$ magnification, pores were visible. Mercury porosimetry was used to measure the porosity in pellet 2 . The average pore diameter was $0.014 \mu \mathrm{m}$. The pore diameter distribution was trimodal. Pore diameters were clustered at 65,6 , and $0.0125 \mu \mathrm{m}$. The total open porosity was estimated at $2 \%$. Open porosity may be larger since pores $>300 \mu \mathrm{m}$ and $<60 \AA$ were not measured. A reduction in open porosity should lead to improved leachresistance. Past work has shown that minor adjustments in hot-pressing conditions (e.g., higher pressures or temperatures) yield denser and more leach resistant materials [9]. This past work is especially relevant since it is concerned with the densification of todo-sodalite. Experiments under different hot-pressing conditions are now planned. 
Table II. Normalized Release Rates from Bonded Zeolite

\begin{tabular}{|c|c|c|c|c|c|c|c|c|c|c|c|c|}
\hline $\begin{array}{c}\text { Pellet } \\
\text { Number }\end{array}$ & $\begin{array}{c}\text { Zeolite } \\
(w t)\end{array}$ & \multicolumn{10}{|c|}{ Normalized Release Rates $\left(\mathrm{g} / \mathrm{m}^{2} \mathrm{~d}\right)$} \\
\hline & & $\mathrm{Al}$ & $\mathrm{Ba}$ & $\mathrm{B}$ & $\mathrm{Ca}$ & $\mathrm{Cs}$ & $\mathrm{K}$ & $\mathrm{Li}$ & $\mathrm{Na}$ & $\mathrm{Si}$ & $\mathrm{Sr}$ & $\mathrm{Y}$ \\
\hline 1 & 67 & 0.30 & 0.06 & 0.30 & 0.14 & 0.55 & 0.63 & 0.64 & 0.71 & 0.26 & 0.10 & $\mathrm{ND}$ \\
\hline 2 & 67 & 0.27 & 0.09 & 0.28 & 0.18 & 0.62 & 0.69 & 0.62 & 0.75 & 0.23 & 0.16 & $\mathrm{ND}$ \\
\hline 3 & 60 & 0.27 & 0.07 & 0.31 & 0.18 & 0.53 & 0.65 & 0.68 & 0.80 & 0.24 & 0.14 & ND \\
\hline 4 & 60 & 0.23 & 0.15 & 0.28 & 0.24 & 0.56 & 0.50 & 0.54 & 0.62 & 0.28 & 0.20 & $\mathrm{ND}$ \\
\hline 5 & 50 & 0.22 & 0.08 & 0.38 & 0.30 & 0.40 & 0.29 & 0.42 & 0.40 & 0.19 & 0.15 & ND \\
\hline$S$ & 50 & 0.22 & 0.12 & 0.32 & 0.31 & 0.39 & 0.33 & 0.36 & 0.30 & 0.24 & 0.24 & ND \\
\hline Average & & 0.25 & 0.095 & 0.31 & 0.23 & 0.51 & 0.52 & 0.54 & 0.60 & 0.24 & 0.17 & \\
\hline Std Dev & & 0.03 & 0.034 & 0.04 & 0.07 & 0.09 & 0.17 & 0.13 & 0.20 & 0.03 & 0.05 & \\
\hline
\end{tabular}

ND $=$ Not detected 
Summary and Future Work

Bonded zeolite was formed by hot pressing a mixture of salt-loaded zeolite and glass frit. Hot pressing at $990 \mathrm{~K}$ did not cause significant volatilization of cesium or any other component. Leach resistance was measured with a modified MCC-1 leach test. The normalized release rates for all elements from bonded zeolite were $<1 \mathrm{~g} / \mathrm{m}^{2} \mathrm{~d}$. These resuits demonstrate that the bonded zeolite may be a suitable waste form for IFR waste salt. Future work will include longer term leach tests, optimization of hot pressing conditions, and mecharical property measurements. Other glasses will also be tested.

\section{References:}

1. J. J. Laidler, Argonne National Laboratory, private communication (1992).

2. M. A. Lewis, D. F. Fischer, and L. J. Smith, "Salt-Occluded Zeoiites as an Immobilization Matrix for Chloride Waste Salt," accepted for publication, J. Am. Ceram. Soc.

3. M. Liquornik and Y. Marcus, "Ion Exchange in Molten Salts II: The Occlusion of Lithium, Sodium, Potassium and Silver Nitrates in the Respective Forms of Zeolite A," Israel J. Chem. 6 , $115-121$ (1968).

4. C. M. Jantzen, N. E. Bibler, D. C. Beam, W. G. Ramsey, and 8. J. Waters, Standard Test Method for Evaluating Nuclear, Hazardous, and Mixed Waste Glass Durability: The Product Consistency Test (PCT), WSRC-TR-90-539, Rev.2, Westinghouse Savannah River Co. (1991).

5. C. M. Jantzen, Evaluation of Experimental Factors that Influence the Application and Discrimination Capability of the Product Consistency Test (U), WSRC-TR-90-526, Rev. 1. Westinghouse Savannah River (1991).

6. T. R. Johnson and R. J. Blaskovitz, Argonne National Laboratory, private communication (1992)

7. Nuclear Waste Materials Handbook, DOE/TIC-11400 (1982).

8. M. J. Plodenic, G. G. Wicks, and N. E. Bibler, An Assessment of Savannah River Borosilicate Glass in the Repository Environment, DP-1629, Savannah Fiver Laboratory (1982).

9. W.I. Winters, The Effect of Hot-Pressing Conditions on the Properties of lodide Sodalite, RHO-LD-153, Rockwell International (1980). 